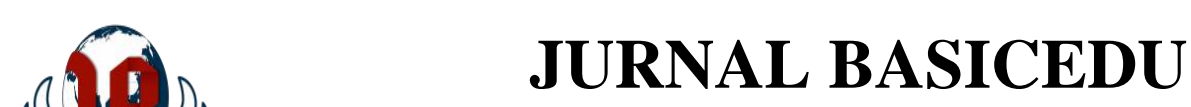

Volume 5 Nomor 3 Tahun 2021 Halaman 1277-1285

Research \& Learning in Elementary Education https://jbasic.org/index.php/basicedu

P AHLAWAN

\title{
Komparasi Model Pembelajaran Problem Based Learning dan Inquiry Learning Ditinjau dari Keterampilan Berfikir Kritis Siswa pada Mata Pelajaran IPA di Sekolah Dasar
}

\author{
Dwi Ratna Efendi ${ }^{1}$, Krisma Widi Wardani ${ }^{2}$ \\ Pendidikan Guru Sekolah Dasar, Unversitas Kristen Satya Wacana, Indonesia ${ }^{1,2}$

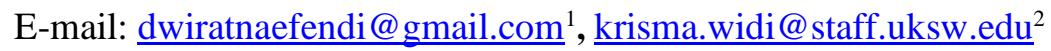

\begin{abstract}
Abstrak
Dalam proses pembelajaran, guru harus mampu mendesain pembelajaran sebaik mungkin yang mampu meningkatkan semangat peserta didik dengan menerapkan model pembelajaran yang mampu meningkatkan keaktifan peserta didik, salah satunya dengan menerapkan model pembelajaran Problem Based Learning atau Inquiry Learning . Penelitian ini bertujuan untuk mengetahui perbandingan model pembelajaran Problem Based Learning dengan Inquiry Learning pada mata pelajaran IPA di SD. Jenis dari penelitian ini adalah penelitian meta-analisis. Data yang digunakan pada penelitian ini dari 20 artikel pada jurnal online. Dari data yang diperoleh, didapatkan skor pretest model pembelajaran Problem Based Learning 59,26\%, sedangkan model Inquiry Learning 52,72\%. Skor posttest model pembelajaran Problem Based Learning 84,56\%, sedangkan model Inquiry Learning 76,94\%. Kemudian, dilakukan uji anova agar mengetahui pengaruh dari masing-masing model. Hasil uji effect size dari kedua model tersebut yang tertera pada kolom partial eta squared dengan besar 0,435 dengan sig. sebesar 0,008. Dengan begitu, dapat disimpulkan bahwa model pembelajaran Problem Based Learning dan Inquiry Learning memiliki dampak sedang terhadap keterampilan berpikir kritis peserta didik pada mata pelajaran IPA. Berdasarkan hasil olah data, model pembelajaran Problem Based Learning lebih efektif dalam meningkatkan keterampilan berpikir kritis pada mata pelajaran IPA di sekolah dasar.
\end{abstract}

Kata kunci: Problem Based Learning, Inquiry Learning, Berpikir Kritis, IPA.

\begin{abstract}
In the learning process, the teacher must be able to design the best possible learning that is able to increase the enthusiasm of students by applying a learning model that is able to increase the activeness of students, one of which is by applying themodel Problem Based Learning or Inquiry Learning. This study aims to determine the comparison of thelearning model Problem Based Learning with Inquiry Learning in science subjects in elementary schools. This type of research is a meta-analysis research. The data used in this study were from 20 articles injournals online. From the data obtained, thescore for pretest themodel of learning was Problem Based Learning 59.26\%, while themodel was Inquiry Learning 52.72\%. Thescore posttest of thelearning model is Problem Based Learning 84.56\%, while themodel is Inquiry Learning $76.94 \%$. Then, the atest was carried out innova order to determine the effect of each model. The results of thetest effect size of the two models are listed in thecolumn partial eta squared with a size of 0.435 with sig. equal to 0.008. Thus, it can be concluded that thelearning model Problem Based Learning and Inquiry Learning has a moderate impact on students' critical thinking skills in science subjects. Based on the results of data processing, learning models Problem Based Learning is more effective in improving critical thinking skills in science subjects in elementary schools.
\end{abstract}

Keywords: Problem Based Learning, Inquiry Learning, Critical Thinking, Science.

Copyright (c) 2021 Dwi Ratna Efendi, Krisma Widi Wardani

Corresponding author :

Email : dwiratnaefendi@gmail.com

DOI : https://doi.org/10.31004/basicedu.v5i3.914

ISSN 2580-3735 (Media Cetak)

ISSN 2580-1147 (Media Online

Jurnal Basicedu Vol 5 No 3 Tahun 2021

p-ISSN 2580-3735 e-ISSN 2580-1147 
1278 Komparasi Model Pembelajaran Problem Based Learning dan Inquiry Learning Ditinjau dari Keterampilan Berfikir Kritis Siswa di Sekolah Dasar - Dwi Ratna Efendi, Krisma Widi Wardani

DOI : https://doi.org/10.31004/basicedu.v5i3.914

\section{PENDAHULUAN}

IPA merupakan salah satu aspek pendidikan sebagai alat untuk mencapai tujuan pendidikan, yaitu membangkitkan individu-individu yang berliterasi IPA (Rahayuni, 2016). Peristiwa yang diangkat dalam literasi IPA adalah peristiwa di dunia nyata yang berhubungan dengan alam dan dekat dengan kehidupan peserta didik. Pembelajaran IPA mempunyai sifat khas yang kompleks karena membutuhkan kemampuan berpikir kritis dalam menganalisis masalah.

Berpikir kritis siswa merupakan salah satu keterampilan hidup yang perlu pelatihan sejak sekolah dasar sebagai bekal untuk peserta didik (Ejin, 2016). Hal tersebut juga yang perlu diketahui oleh guru pentingnya melatih keterampilan berpikir kritis siswa. Berpikir kritis memiliki arti merefleksikan masalah secara lebih dalam, selalu mempertahankan pikiran untuk tetap terbuka bagi berbagai pendekatan dan sudut pandang yang berbeda, tidak langsung percaya pada informasi yang didapatkan dari beberapa sumber yang berbentuk tulisan atau lisan, serta berpikir secara reflektif daripada hanya menerima ide tanpa memiliki pemahaman dan evaluasi signifikan (Hidayati et al., 2019). Berpikir kritis adalah cara berpikir yang disiplin dan dikendalikan kesadaran (Maqbullah et al., 2018). Dalam meningkatkan keterampilan berpikir kritis pada peserta didik, guru menggunakan model pembelajaran yang sesuai dalam proses belajar-mengajar.

Model pembelajaran adalah kerangka konseptual yang dipakai untuk ketentuan dasar dalam pembelajaran (Indrawati, 2017). Dapat disimpulkan bahwa model pembelajaran adalah kerangka penyajian materi yang digunakan guru sebagai ketentuan dasar dalam proses belajar-mengajar. Model pembelajaran yang digunakan dalam penelitian ini adalah model Problem Based Learning dan Inquiry Learning. Problem Based Learning adalah model pembelajaran yang menggunakan masalah yang tidak hanya mentransfer ilmu dari guru ke peserta didik, tetapi juga ikut andil dalam pemikiran kerja sama antara guru dan peserta didik, peserta didik dengan peserta didik lain untuk mendapatkan inti pemecahan dari masalah yang sedang dibahas (Suari, 2018).

Model pembelajaran Inquiry Learning merupakan model pembelajaran yang menekankan peserta didik untuk mencari tahu dan membangun pengetahuannya sendiri. Model pembelajaran Inquiry Learning merupakan model yang dikembangkan supaya peserta didik mampu menemukan dan menggunakan berbagai sumber informasi dan ide-ide agar pemahaman peserta didik tentang berbagai masalah, topik, atau isu tertentu dapat meningkat (Setianingsih, 2016). Dapat disimpulkan bahwa model pembelajaran Inquiry Learning merupakan model pembelajaran yang merangsang kemampuan peserta didik agar dapat berpikir kritis dalam menyelesaikan masalah yang diberikan oleh guru dengan cara mengumpulkan informasi secara mandiri.

Sudah banyak peneliti yang melakukan penelitian tentang peningkatan berpikir kritis dengan menggunakan model pembelajaran Problem Based Learning dan Inquiry Learning. Di antaranya adalah penelitian yang dilakukan Syahroni Ejin, dari hasil penelitiannya didapatkan kesimpulan bahwa pembelajaran menggunakan model pembelajaran Problem Based Learning dapat meningkatkan keterampilan berpikir kritis pada peserta didik (Ejin, 2016). Kemudian, dari penelitian yang dilakukan oleh Shofiyah, Tati Sumiati, dan Idat Muqodas didapatkan kesimpulan bahwa keterampilan berpikir kritis peserta didik dalam pembelajaran IPA mengalami peningkatan dengan menggunakan model pembelajaran Problem Based Learning (Maqbullah et al., 2018). Sedangkan dalam penelitian yang dilakukan Krisda Amelia dan Suhandi Astuti didapatkan hasil bahwa pembelajaran dengan menggunakan model Inquiry Learning mampu meningkatkan kemampuan berpikir kritis pada peserta didik (Amelia \& Astuti, 2020). Lalu, pada penelitian yang dilakukan Siti Aminah, Tri Saptuti, dan Kartika Chrysti, membuktikan bahwa kemampuan berpikir kritis pada peserta didik meningkat setelah menggunakan model pembelajaran Inquiry Learning (Aminah et al., 2017) .

Beberapa contoh penelitian di atas membuktikan bahwa sudah ada banyak penelitian yang membahas tentang penggunaan model pembelajaran Problem Based Learning dan pembelajaran Inquiry Learning. Model 
1279 Komparasi Model Pembelajaran Problem Based Learning dan Inquiry Learning Ditinjau dari Keterampilan Berfikir Kritis Siswa di Sekolah Dasar - Dwi Ratna Efendi, Krisma Widi Wardani

DOI : https://doi.org/10.31004/basicedu.v5i3.914

Problem Based Learning dan Inquiry Learning merupakan model pembelajaran yang sama-sama berbasis masalah, di mana peserta didik dapat membangun pengetahuannya sendiri melalui masalah yang disajikan oleh pendidik dengan begitu peserta didik dapat meningkatkan keterampilan berpikir kritis. Dari banyaknya penelitian yang telah dilakukan peneliti terdahulu, maka perlu dikaji ulang tentang bagaimana pengaruh kedua model pembelajaran tersebut jika dibandingkan. Dengan begitu, pada penelitian yang dilakukan penulis untuk mengetahui perbandingan atau komparasi dari model pembelajaran Problem Based Learning dan Inquiry Learning terhadap pengaruhnya pada keterampilan berpikir kritis pada mata pelajaran IPA di SD.

\section{METODE PENELITIAN}

Metode yang digunakan dalam penelitian ini adalah meta-analisis. Meta-analisis adalah penelitian yang dilakukan dengan cara mencari dan mengumpulkan artikel yang sesuai dengan judul yang akan diteliti dari jurnal online, merangkum data, melakukan review, dan melakukan analisis hasil data dari penelitian yang sudah ada secara statistika agar peneliti dapat memperoleh hasil yang valid. Penelitian meta-analisis dilakukan dengan cara mengumpulkan artikel, merangkum data, melakukan review, dan melakukan analisis penelitian yang menggunakan model pembelajaran Problem Based Learning dan Inquiry Learning terhadap keterampilan berpikir kritis peserta didik pada mata pelajaran IPA di sekolah dasar. Masing-masing model menggunakan 10 artikel, jadi artikel yang digunakan pada penelitian ini ada 20. Di mana artikel yang digunakan adalah artikel mengenai model pembelajaran Problem Based Learning dan Inquiry Learning di sekolah dasar yang diterbitkan dalam rentang waktu 2012-2021. Dari data skor posttest dapat dilihat pengaruh model pembelajaran Problem Based Learning dan Inquiry Learning jika digunakan dalam proses pembelajaran. Setelah itu, data juga diproses dengan menggunakan aplikasi SPSS 25 for windows, kemudian akan diketahui effect size dari model pembelajaran, sehingga peneliti dapat memperoleh kesimpulan model mana yang pengaruhnya lebih besar dalam pembelajaran.

\section{HASIL DAN PEMBAHASAN}

Penelitian ini dilakukan untuk mengetahui adanya komparasi atau perbandingan efektivitas dalam penggunaan model pembelajaran Problem Based Learning dan Inquiry Learning terhadap keterampilan berpikir kritis peserta didik pada pembelajaran IPA di sekolah dasar. Pada penelitian ini, penentuan hipotesis yang diuji apakah diterima atau ditolak dengan menggunakan uji hipotesis.

Persentase rata-rata dari peningkatan keterampilan berpikir kritis dalam mata pelajaran IPA dengan menggunakan model pembelajaran Problem Based Learning mendapatkan skor terendah 16,52\% dan skor tertinggi 32,58\% dengan rata-rata sebesar $23,11 \%$. Persentase dari rerata keterampilan berpikir kritis sebelum menggunakan model pembelajaran Problem Based Learning adalah 59,26\%, sedangkan setelah menggunakan model pembelajaran Problem Based Learning meningkat menjadi 84,56\%.

Rerata persentase dari peningkatan keterampilan berpikir kritis dalam mata pelajaran IPA dengan menggunakan model pembelajaran Inquiry Learning dengan skor terendah 7,91\% dan skor tertinggi 39,5\% dengan rata-rata $19,23 \%$. Persentase rata-rata keterampilan berpikir kritis sebelum menggunakan model pembelajaran Inquiry Learning adalah 52,72\%, sedangkan setelah menggunakan model pembelajaran Inquiry Learning meningkat menjadi 76,94\%.

Berdasarkan analisis uji anova yang telah dilakukan pada model pembelajaran Problem Based Learning menggunakan 10 artikel dengan rata-rata skor posttest 32,8\%. Sedangkan pada model pembelajaran Inquiry 
1280 Komparasi Model Pembelajaran Problem Based Learning dan Inquiry Learning Ditinjau dari Keterampilan Berfikir Kritis Siswa di Sekolah Dasar - Dwi Ratna Efendi, Krisma Widi Wardani

DOI : https://doi.org/10.31004/basicedu.v5i3.914

Learning dengan menggunakan 10 artikel memiliki rata-rata posttest 39,5\%. Sehingga, model pembelajaran Problem Based Learning mempunyai hasil lebih tinggi dibandingkan model pembelajaran Inquiry Learning.

Berdasarkan uji anova dengan univariate, siginifikasi sebesar 0,048 yang artinya lebih kecil dari 0,05 $(0,048<0,05)$. Di mana $\mathrm{f}$ hitung $>\mathrm{f}$ tabel, yaitu $5,272>3,59$. Hal ini membuktikan bahwa $\mathrm{H}_{\mathrm{o}}$ ditolak dan $\mathrm{H}_{\mathrm{a}}$ diterima. Sehingga, kedua model tersebut memilik perbedaan efektivitas signifikan.

Setelah melakukan uji anova, dapat diketahui effect size dari kedua model tersebut yang tertera pada kolom partial eta squared dengan besar 0,435 dengan sig. sebesar 0,008. Dengan demikian dapat disimpulkan bahwa model pembelajaran Problem Based Learning dan Inquiry Learning memberikan dampak sedang terhadap keterampilan berpikir kritis peserta didik pada mata pelajaran IPA.

Tabel 1

Persentase Peningkatan Keterampilan Berpikir Kritis pada Mata Pelajaran IPA dengan Menggunakan Model Pembelajaran Problem Based Learning

\begin{tabular}{llccc}
\hline No. & Kode Data & \multicolumn{3}{c}{ Persentase (\%) } \\
\cline { 3 - 5 } & & Skor Pretest & Skor Posttest & Peningkatan \\
\hline 1. & 1PB & 75,20 & 96,50 & 21,30 \\
\hline 2. & 2PB & 57,02 & 80,30 & 23,28 \\
\hline 3. & $3 \mathrm{~PB}$ & 61,08 & 77,60 & 16,52 \\
\hline 4. & 4PB & 48,20 & 77,42 & 29,22 \\
\hline 5. & $5 \mathrm{~PB}$ & 41,70 & 86,20 & 44,50 \\
\hline 6. & $6 \mathrm{~PB}$ & 56,00 & 84,32 & 28,32 \\
\hline 7. & $7 \mathrm{~PB}$ & 57,20 & 75,80 & 18,60 \\
\hline 8. & $8 \mathrm{~PB}$ & 62,00 & 80,05 & 18,05 \\
\hline 9. & $9 \mathrm{~PB}$ & 60,22 & 92,80 & 32.58 \\
\hline 10. & 10PB & 74,00 & 94,68 & 20.68 \\
\hline & Rerata & 59,26 & 84,56 & 23.11 \\
\hline
\end{tabular}

Berdasarkan tabel di atas, dapat diketahui bahwa dengan menggunakan model pembelajaran PB (Problem Based Learning) dapat meningkatkan keterampilan berpikir kritis peserta didik pada mata pelajaran IPA. Rata-rata peningkatan kemampuan berpikir kritis dengan menggunakan model pembelajaran Problem Based Learning adalah 23,11\%, dengan persentase rata-rata tertinggi sebesar 50,87\%, dan rata-rata terendah sebesar $16,52 \%$. Persentase rata-rata keterampilan berpikir kritis peserta didik pada tahap pretest adalah $59,26 \%$, sedangkan rata-rata keterampilan berpikir kritis pada tahap posttest adalah $84,56 \%$. Di mana dalam proses pembelajaran sebelum menggunakan model Problem Based Learning dan setelah menggunakan model pembelajaran Problem Based Learning mengalami peningkatan sebesar 25,3\%.

Tebel 2

Persentase Peningkatan Keterampilan Berpikir Kritis pada Mata Pelajaran IPA dengan Menggunakan Model Pembelajaran Inquiry Learning

\begin{tabular}{llccc}
\hline \multirow{2}{*}{ No. } & \multirow{2}{*}{ Kode Data } & \multicolumn{3}{c}{ Presentase (\%) } \\
\cline { 3 - 5 } & & Skor Pretest & Skor Posttest & Peningkatan \\
\hline 1. & 1IL & 52,86 & 66,28 & 13,42 \\
\hline 2. & 2IL & 84,86 & 92,77 & 7,91 \\
\hline 3. & 3IL & 42,30 & 81,80 & 39,5 \\
\hline 4. & 4IL & 54,85 & 82,00 & 27,15 \\
\hline 5. & 5IL & 56,00 & 70,10 & 14,1 \\
\hline 6. & 6IL & 50,00 & 62,86 & 12,86 \\
\hline 7. & 7IL & 53,45 & 74,09 & 20,64 \\
\hline
\end{tabular}


1281 Komparasi Model Pembelajaran Problem Based Learning dan Inquiry Learning Ditinjau dari Keterampilan Berfikir Kritis Siswa di Sekolah Dasar - Dwi Ratna Efendi, Krisma Widi Wardani DOI : https://doi.org/10.31004/basicedu.v5i3.914

\begin{tabular}{llccc}
\hline 8. & 8IL & 62,80 & 72,00 & 9,2 \\
\hline 9. & 9IL & 78,15 & 87,50 & 9,35 \\
\hline 10. & 10IL & 42,00 & 80,00 & 38 \\
\hline & Rerata & 52,72 & 76,94 & 19,23 \\
\hline
\end{tabular}

Berdasarkan tabel di atas, dapat diketahui bahwa dengan menggunakan model pembelajaran IL (Inquiry Learning) dapat meningkatkan keterampilan berpikir kritis peserta didik pada mata pelajaran IPA. Rata-rata peningkatan kemampuan berpikir kritis dengan menggunakan model pembelajaran Inquiry Learning adalah terendah $19,23 \%$ dengan persentase tertinggi sebesar 39,5\%, dan rata-rata terendah sebesar 7,91\%. Persentase rata-rata keterampilan berpikir kritis peserta didik pada tahap pretest adalah $52,72 \%$, sedangkan rata-rata keterampilan berpikir kritis pada tahap posttest adalah 76,94\%. Di mana dalam proses pembelajaran sebelum menggunakan model Inquiry Learning dan sesudah menggunakan model pembelajaran Inquiry Learning mengalami kenaikan sebesar 24,22\%.

Tabel 3

Komparasi Hasil Pengukuran Kemampuan Berpikir Kritis

\begin{tabular}{cccc}
\hline \multirow{2}{*}{ Pengukuran } & \multicolumn{2}{c}{ Rata-rata Skor (Mean) } & \multirow{2}{*}{ Selisih } \\
\cline { 2 - 3 } & Problem Based Learning & Inquiry Learning & \\
\hline Pretest & 59,26 & 52,72 & 6,54 \\
\hline Posttest & 84,56 & 76,94 & 7,62 \\
\hline
\end{tabular}

Berdasarkan hasil pengukuran komparasi rerata pada tabel di atas rata-rata skor pretest antara model Problem Based Learning dan Inquiry Learning memiliki selisih 6,54\%. Sedangkan rata-rata skor posttest antara model Problem Based Learning dan Inquiry Learning adalah 7,62\%.

Tabel 4

Hasil Analisis Data menggunakan Uji Anova

\section{Descriptive Statistics}

\begin{tabular}{|c|c|c|c|}
\hline model pembelajaran & Mean & Std. Deviation & $N$ \\
\hline problem based learning & 84.5670 & 7.67586 & 10 \\
\hline inquiry learning & 76.9400 & 9.49785 & 10 \\
\hline Total & 80.7535 & 9.27080 & 20 \\
\hline
\end{tabular}

Berdasarkan hasil uji anova yang dilakukan pada model pembelajaran Problem Based Learning, ada 10 artikel dengan rata-rata 84,5670. Sedangkan pada model pembelajaran Inquiry Learning dengan 10 artikel memiliki rata-rata 76,9400. Sehingga, dapat disimpulkan bahwa terdapat perbedaan antara model Problem Based Learning dengan Inquiry Learning. Di mana model Problem Based Learning hasilnya lebih tinggi daripada Inquiry Learning. 
1282 Komparasi Model Pembelajaran Problem Based Learning dan Inquiry Learning Ditinjau dari Keterampilan Berfikir Kritis Siswa di Sekolah Dasar - Dwi Ratna Efendi, Krisma Widi Wardani DOI : https://doi.org/10.31004/basicedu.v5i3.914

Tabel 5

Hasil Analisis Uji Anova

Tests of Between-Subjects Effects

Dependent Variable: posttest

\begin{tabular}{|c|c|c|c|c|c|c|}
\hline Source & $\begin{array}{c}\text { Type III Sum } \\
\text { of Squares }\end{array}$ & df & Mean Square & $\mathrm{F}$ & Sig. & $\begin{array}{c}\text { Partial Eta } \\
\text { Squared }\end{array}$ \\
\hline Corrected Model & $710.282^{a}$ & 2 & 355.141 & 6.543 & .008 & .435 \\
\hline Intercept & 2542.125 & 1 & 2542.125 & 46.835 & .000 & .734 \\
\hline pretest & 419.426 & 1 & 419.426 & 7.727 & .013 & .313 \\
\hline modelpembelajaran & 246.194 & 1 & 246.194 & 4.536 & .048 & .211 \\
\hline Error & 922.726 & 17 & 54.278 & & & \\
\hline Total & 132055.563 & 20 & & & & \\
\hline Corrected Total & 1633.007 & 19 & & & & \\
\hline
\end{tabular}

a. R Squared $=.435$ (Adjusted R Squared $=.368$ )

Berdasarkan hasil uji anova, pada baris model pembelajaran memiliki angka signifikasi sebesar 0,048. F hitung diperoleh 3,59 dan $\mathrm{f}$ tabel yang diperoleh adalah 5,272.

Berikut ini interpretasi Effect Size sebagai berikut.

Tabel 6

Interpretasi Effect Size

\begin{tabular}{cc}
\hline Effect Size & Interpretasi \\
\hline $0<\mathrm{d}<0,2$ & Kecil \\
\hline $0,2<\mathrm{d} \leq 0,5$ & Sedang \\
\hline $0,5<\mathrm{d} \leq 0,08$ & Besar \\
\hline $\mathrm{d}>0,8$ & Sangat Besar \\
\hline
\end{tabular}

Berikut hasil analisis effect size yang berguna untuk melihat perbedaan antara model pembelajaran Problem Based Learning dan Inquiry Learning.

Tabel 7

Uji Effect Size Menggunakan Uji Anova

Tests of Between-Subjects Effects

\begin{tabular}{|c|c|c|c|c|c|c|}
\hline Source & $\begin{array}{c}\text { Type III Sum } \\
\text { of Squares }\end{array}$ & df & Mean Square & $\mathrm{F}$ & Sig. & $\begin{array}{l}\text { Partial Eta } \\
\text { Squared }\end{array}$ \\
\hline Corrected Model & $710.282^{\mathrm{a}}$ & 2 & 355.141 & 6.543 & .008 & .435 \\
\hline Intercept & 2542.125 & 1 & 2542.125 & 46.835 & .000 & .734 \\
\hline pretest & 419.426 & 1 & 419.426 & 7.727 & .013 & .313 \\
\hline modelpembelajaran & 246.194 & 1 & 246.194 & 4.536 & .048 & .211 \\
\hline Error & 922.726 & 17 & 54.278 & & & \\
\hline Total & 132055.563 & 20 & & & & \\
\hline Corrected Total & 1633.007 & 19 & & & & \\
\hline
\end{tabular}

a. R Squared $=.435$ (Adjusted R Squared $=.368$ )

Berdasarkan tabel, effect size dengan menggunakan uji anova pada model pembelajaran Problem Based Learning dan Inquiry Learning, memperoleh hasil 0,435 pada kolom corrected model memiliki nilai sig. sebesar 0,008. Jika dilihat pada tabel interpretasi effect size, hal ini menunjukkan model pembelajaran 
1283 Komparasi Model Pembelajaran Problem Based Learning dan Inquiry Learning Ditinjau dari Keterampilan Berfikir Kritis Siswa di Sekolah Dasar - Dwi Ratna Efendi, Krisma Widi Wardani

DOI : https://doi.org/10.31004/basicedu.v5i3.914

Problem Based Learning dan Inquiry Learning memberikan dampak sedang pada keterampilan berpikir kritis pada mata pelajaran IPA di SD.

Model pembelajaran Problem Based Learning memiliki skor lebih tinggi dibandingkan Inquiry Learning. Dengan begitu, model pembelajaran Problem Based Learning lebih efektif digunakan dalam pembelajaran dibandingkan model Inquiry Learning, yang dibuktikan dengan skor posttest untuk model pembelajaran Problem Based Learning sebesar 84,56\%, sedangkan model Inquiry Learning sebesar 79,94\%. Hal ini didukung dengan penelitian yang telah dilakukan (Khomaidah \& Koeswanti, 2020) memperoleh hasil bahwa model Problem Based Learning lebih efektif digunakan dibandingkan model Inquiry, di mana rerata untuk Problem Based Learning adalah 79,73 sedangkan untuk model Inquiry adalah 75,63.

\section{KESIMPULAN}

Berdasarkan pada hasil dan pembahasan, dapat diambil kesimpulan bahwa model pembelajaran Problem Based Learning lebih efektif dalam meningkatkan keterampilan berpikir kritis pada mata pelajaran IPA di sekolah dasar. Hal tersebut dapat dilihat dari hasil uji anova dengan rerata 84,5670 sedangkan model pembelajaran Inquiry Learning memiliki rata-rata 76,9400. Dari rata-rata tersebut terlihat bahwa rata-rata model pembelajaran Problem Based Learning lebih tinggi. Berdasarkan effect size dengan model pembelajaran Problem Based Learning dan Inquiry Learning, memperoleh hasil Partial Eta Squared 0,435, pada kolom corrected model dengan nilai sig. sebesar 0,008. Dengan demikian dapat disimpulkan bahwa model pembelajaran Problem Based Learning dan Inquiry Learning memberikan pengaruh sedang terhadap keterampilan berpikir kritis pada mata pelajaran IPA di SD.

\section{UCAPAN TERIMA KASIH}

Peneliti mengucapkan terima kasih kepada Tuhan Yang Maha Esa,yang selalu memberikan kemampuan kepada penulis untuk menyelesaikan artikel ini, kepada kedua orang tua dan keluarga yang selalu memberikan dukungan dan semangat, kepada Miss Krisma Widi Wardani, S.Pd., M.Pd., dan kepada teman-teman yang sudah memberikan bantuan kepada penulis sehingga penulis dapat menyelesaikan artikel ini.

\section{DAFTAR PUSTAKA}

Amelia, K., \& Astuti, S. (2020). Efektivitas Penerapan Model Discovery Learning dan Inquiry Terhadap Keterampilan Berpikir Kritis Pembelajaran Subtema Perubahan Bentuk Energi Kelas III Gugus Sudirman. Jurnal Ilmiah Wahana Pendidikan, 6(2), 151-157. https://doi.org/10.5281/zenodo.3742727

Aminah, S., Susiani, T. S., \& Suryandari, K. C. (2017). Peningkatan Keterampilan Berpikir Kritis Melalui Model Pembelajaran Inkuiri Terbimbing Dengan Multimedia Dalam Pembelajaran IPA Tentang Energi. Kalam Cendekia, 5(3), 261-265.

Budiartini, N. L. O., Arcana, I. N., Margunayasa, I. G., \& Pgsd, J. (2013). PENGARUH MODEL PEMBELAJARAN INQUIRI TERBIMBING TERHADAP KEMAMPUAN BERPIKIR KRITIS IPA SISWA KELAS V DI SD 7 DATAH Universitas Pendidikan Ganesha. Mimbar Pgsd .... https://ejournal.undiksha.ac.id/index.php/JJPGSD/article/view/891

Ejin, S. (2016). Jurnal Pendidikan Volume 1 Nomor 1 Tahun. 1, 65-71.

Hidayati, N., Setyosari, P., \& Soepriyanto, E. (2019). Kompetensi Technological Pedagogical Content Knowledge (TPACK) Guru SOSHUM Setingkat SMA. Jurnal Kajian Teknologi Pendidikan, 1(4), 291298. 
1284 Komparasi Model Pembelajaran Problem Based Learning dan Inquiry Learning Ditinjau dari Keterampilan Berfikir Kritis Siswa di Sekolah Dasar - Dwi Ratna Efendi, Krisma Widi Wardani DOI : https://doi.org/10.31004/basicedu.v5i3.914

Indrawati. (2017). Perencanaan Pembelajaran Fisika: Model-model Pembelajaran. Modul, 35.

Islam, F. M., Harjono, N., \& Airlanda, G. S. (2018). Penerapan Model Problem Based Learning untuk Meningkatkan Berpikir Kritis dan hasil Belajar IPA dalam Tema 8 Kelas 4 SD. Jurnal Mitra Pendidikan, 2(7), 613-628.

Jayadinata, A. K., \& Gusrayani, D. (2016). Pengaruh Model Pembelajaran Inkuiri Terbimbing Terhadap Kemampuan Berpikir Kritis Siswa Pada Materi Energi Bunyi. Jurnal Pena Ilmiah, 1(1), 51-60. https://doi.org/10.23819/pi.v1i1.2931

Khomaidah, S., \& Koeswanti, H. D. (2020). Efektivitas Pembelajaran Problem Based Learning dan Guided Inquiry Terhadap Kemampuan Berpikir Kritis Siswa Sekolah Dasar. Jurnal Basicedu, 4(2), 371-378. https://doi.org/10.31004/basicedu.v4i2.356

Kumullah, R., Djatmika, E. T., \& Yulianti, L. (2018). Kemampuan berpikir kritis dan penguasaan konsep siswa dengan Problem Based Learning pada materi sifat cahaya". Teori, Pnelitian Dan Pengembangan, 3(12), 1583-1586. http://journal.um.ac.id/index.php/jptpp/

Kurniawati, A., Festiyed, \& Asrizal. (2019). Meta-Analisis Efektifitas Model Inkuiri Terbimbing Terhadap Keterampilan Proses Sains Dan Kemampuan Berfikir Kritis Peserta Didik. Pillar of Physics Education, 12(4), 849-856.

Mahakam, J. P., Stai, M., Hikmah, D., Barat, A., Kab, N. M., \& Barat, A. (2018). Penerapan metode inquiry untuk meningkatkan kemampuan berpikir kritis pada materi bumi dan alam semesta siswa kelas $v$ sekolah dasar. 3(1).

Maqbullah, S., Sumiati, T., \& Muqodas, I. (2018). Penerapan Model Problem Based Learning (Pbl) Untuk Meningkatkan Kemampuan Berpikir Kritis Siswa Pada Pembelajaran Ipa Di Sekolah Dasar. Metodik Didaktik, 13(2), 106-112. https://doi.org/10.17509/md.v13i2.9500

Nugraha, A. J., Suyitno, H., \& Susilaningsih, E. (2017). Analisis Kemampuan Berpikir Kritis Ditinjau dari Keterampilan Proses Sains dan Motivasi Belajar melalui Model PBL. Journal of Primary Education, 6(1), 35-43. https://doi.org/10.15294/jpe.v6i1.14511

Nurhayati, A. R., Jayadinata, A. K., \& Sujana, A. (2017). Keterampilan Berpikir Kritis Siswa Kelas V Pada Materi Daur. Jurnal Pena Ilmiah, 2(1), 1061-1070. http://ejournal.upi.edu/index.php/penailmiah/article/view/11255

Purbarani, D. A., Dantes, N., \& Adnyana, P. B. (2018). Pengaruh Problem Based Learning Berbantuan Media Audio Visual Terhadap Kemampuan Berpikir Kritis Dan Hasil Belajar Ipa Di Sekolah Dasar. PENDASI: Jurnal Pendidikan Dasar Indonesia, 2(1), 24-34. https://doi.org/10.23887/jpdi.v2i1.2689

Rahayuni, G. (2016). Hubungan Keterampilan Berpikir Kritis Dan Literasi Sains Pada Pembelajaran Ipa Terpadu Dengan Model Pbm Dan Stm. Jurnal Penelitian Dan Pembelajaran IPA, 2(2), 131. https://doi.org/10.30870/jppi.v2i2.926

Rahman, A., \& Ristiana, E. (2020). Pengaruh Model PBL Terhadap Kemampuan Berpikir Kritis dan Pemahaman Konsep IPA Siswa Kelas V SDN 30 Sumpangbita. Jurnal Pendidikan, 4(1), 29-41.

Sarifudin, \& Evendi, H. (2020). Jurnal Mitra Pendidikan ( JMP Online ). Jurnal Mitra Pendidikan, 4(1), 1-9. http://www.e-jurnalmitrapendidikan.com/index.php/e-jmp/article/view/737/473

Setianingsih, N. P. Y. (2016). Penerapan Model Pembelajaran Inkuiri Menggunakan Media Konkret Untuk Meningkatkan Aktivitas Dan Penguasaan Kompetensi Pengetahuan IPA. E-Journal PGSD Universitas $\begin{array}{llllll}\text { Pendidikan Ganesha } & \text { Mimbar } & \text { PGSD, } & 6 & \text { No. } & 1(1) \text {. }\end{array}$ https://ejournal.undiksha.ac.id/index.php/JJPGSD/article/view/7142/4871

Suari, N. putu. (2018). Penerapan Model Pembelajaran Problem Based Learning untuk Meningkatkan Motivasi Belajar IPA. In Jurnal Ilmiah Sekolah Dasar (Vol. 2, Issue 3). https://doi.org/10.23887/jisd.v2i3.16138

Supriyantoro, D., Sumbawati, M. S., \& Sitompul, N. C. (2019). Pengembangan Perangkat Pembelajaran IPA 
1285 Komparasi Model Pembelajaran Problem Based Learning dan Inquiry Learning Ditinjau dari Keterampilan Berfikir Kritis Siswa di Sekolah Dasar - Dwi Ratna Efendi, Krisma Widi Wardani DOI : https://doi.org/10.31004/basicedu.v5i3.914

dengan Model Problem Based Learning Berbasis Outdoor Learning. Jurnal Pijar Mipa, 14(2), 130-143. https://doi.org/10.29303/jpm.v14i2.1136

Utama, K. H., \& Kristin, F. (2020). Meta-Analysis Pengaruh Model Pembelajaran Problem Based Learning (PBL) Terhadap Kemampuan Berpikir Kritis IPA Di Sekolah Dasar. Jurnal Basicedu, 4(4), 889-898. https://doi.org/10.31004/basicedu.v4i4.482 